\title{
= EQUALITAS
}

\section{Economics of Inequality and Poverty Analysis}

\author{
EQUALITAS Working Paper No. 9
}

Unemployment persistence: Not only stigma but discouragement too

Sara Ayllón 


\title{
Unemployment persistence: Not only stigma but discouragement too
}

\author{
Sara Ayllón ${ }^{1}$ \\ Department of Economics \\ Universitat de Girona
}

\begin{abstract}
This paper shows how stigma effects and discouragement counter-balance as sources of state dependence in unemployment throughout the business cycle.
\end{abstract}

Keywords: state dependence in unemployment, stigma effects, discouragement, Spain JEL classification: J64, C23

\section{Introduction}

Literature has shown that unemployment suffers from a certain degree of persistence (Arulampalam et $a l .$, 2000; Stewart, 2007). On the one hand, state dependence in unemployment can be explained by observed and unobserved characteristics that persist across time and make one more likely to be successively unemployed. On the other hand, it has been shown that experiencing unemployment in a given period increases in itself the chances of suffering unemployment again in the future. This scarring effect is known as genuine state dependence. The sources of genuine state dependence in unemployment may be due to the disincentive effects of unemployment insurance, the decay of human capital, the decline in search intensity, discouragement or habituation, and stigma effects.

In this paper, we focus on stigma effects and discouragement as sources of state dependence in unemployment. ${ }^{2}$ Several authors have shown that stigma effects exist: employers are more reluctant to employ someone who has been unemployed for some time than someone who has moved directly from job to job or has been unemployed less often and for shorter periods (Blau and Robins, 1990; Clark et al., 2001; Lockwood, 1991 and Omori, 1997). Biewen and Steffes (2010), conforming with Lockwood's (1991) hypothesis, have recently shown that when the unemployment rate rises and deviates from its trend, state dependence in unemployment decreases, indicating that employers are less suspicious about unemployed individuals during periods of economic downturn. On the contrary, they stigmatise individuals that are unemployed when the unemployment rate is low. When the disadvantageous effect of past unemployment status interacts with the level of past unemployment, as suggested in Omori (1997), no significant effects are found -leading the authors to conclude that evidence for stigma effects in Germany is relatively weak.

However, throughout their paper, Biewen and Steffes (2010) assume that the discouragement of unemployed individuals is constant throughout the business cycle and does not depend on the unemployment rate. Here we find more plausible the idea that when the unemployment rate rises, individuals' discouragement increases as they

\footnotetext{
${ }^{1}$ Correspondence to: C/Universitat de Girona 10, 17071 Girona (Spain). Phone: +34972418779. Fax: +34972418032. E-mail: sara.ayllon@udg.edu

${ }^{2}$ For the remainder of the paper, we refer to genuine state dependence when describing state dependence.
} 
are aware that it has become more difficult to find a job. As a result, we expect state dependence in unemployment to be positive and significant when the unemployment rate rises and the discouragement of workers does so in parallel. So, this paper is innovative in explaining the persistence of unemployment throughout the business cycle not only with stigma effects but also discouragement while using the same methodology as Biewen and Steffes (2010).

\section{Data}

Our analysis is based on the Spanish component of the European Community Household Panel (ECHP), 1994-2001. The sample consists of an unbalanced panel of 4,160 men (16,126 observations). Women are excluded as it is difficult to predict the effect of career interruptions on the results. Furthermore, we restrict the analysis to those aged over 25 and below 56 in order to avoid the interference of education or early retirement decisions. We exclude self-employed workers and individuals in the agriculture, forestry, fishing, hotel and restaurant industries given that seasonal unemployment is important in these sectors.

We predict the cyclical unemployment risk by regressing the unemployment rate against a linear time trend in each of the Spanish regions. The residuals are interpreted as deviations from the unemployment rate trend. Figure A.1 in the Appendix shows that even when our sample only includes eight years, there is enough variation in the data [$3.67 \%, 4.38 \%]^{3}$

In order to measure discouragement among unemployed individuals, we use the answers to the question: 'How good do you think are your chances of finding the kind of job you are looking for within the next 12 months?'. There are four possible answers: 'good', 'not good not bad', 'bad' and 'very bad'. ${ }^{4}$ Naturally, we believe individuals feel discouraged if they think their chances of finding a job are low. Note that we include the category 'Unemployed not looking for a job', individuals that we also wish to consider in our analysis.

As shown in Table 1, the percentage of unemployed individuals that feel discouraged about finding a job goes hand in hand with the unemployment rate. Note, for instance, that in 1996, when the unemployment rate was highest (23.9\%), about $38.7 \%$ of the unemployed would state that their chances of finding a job were very bad. But when the unemployment rate was the lowest $(12.0 \%)$ in 2001 , only $13.7 \%$ of the unemployed would answer in the same way. Moreover, these results are independent of the percentage of unemployed that declared that they were looking for a job.

\section{[TABLE_1]}

As for the other explanatory variables, we follow a standard specification that includes age, age squared, marital status, number of children in the household, educational qualifications, immigrant origin and, finally, region and year dummies.

\footnotetext{
${ }^{3}$ We do not know of any other annual panel that is longer and includes the variables needed for our analysis (namely, discouragement).

${ }^{4}$ Note that this question is answered by anyone in the survey who is looking for a job regardless of their activity status.
} 


\section{Econometric model}

In order to obtain a baseline against which to compare, we first estimate a dynamic random-effects probit as in Biewen and Steffes (2010):

$u_{i t}^{*}=\gamma_{1}^{\prime} u_{i t-1}+\gamma_{2}^{\prime} y_{t} u_{i t-1}+\gamma_{3}^{\prime} X_{i t}+v_{i}+\mu_{i t}$

where $i=1,2, \ldots N$ refers to adult individuals and $t=1, \ldots, T$ are the number of periods under study. $u_{i t-1}$ is the individual unemployment status of the previous wave, so we expect $\gamma_{1}$ to be positive and significant capturing the importance of state dependence in unemployment. $y_{t} u_{i t-1}$ is the interaction between past unemployment status and the cyclical unemployment risk, so we believe $\gamma_{2}$ to be negative, meaning that the consequences of having been unemployed are smaller when the unemployment rate deviates positively from its trend. This would imply the existence of stigma effects as state dependence would be higher for the unemployed in periods of economic growth.

Our new specification adds discouragement as a source of state dependence. Formally,

$u_{i t}^{*}=\beta_{1}^{\prime} u_{i t-1} d_{i t-1}+\beta_{2}^{\prime} y_{t} u_{i t-1} d_{i t-1}+\beta_{3}^{\prime} y_{t} d_{i t-1}+\beta_{4}^{\prime} X_{i t}+c_{i}+\varepsilon_{i t}$

where $u_{i t-1} d_{i t-1}$ is the interaction between the individual feeling of discouragement when unemployed at $t-1$. We expect $\beta_{1}$ to be positive as state dependence in unemployment may be reinforced if the individual feels his/her chances of finding a job are low. $y_{t} u_{i t-1} d_{i t-1}$ is the interaction between the cyclical unemployment risk, past unemployment and discouragement. If there is stigmatisation, $\beta_{2}$ should be negative. $y_{t} d_{i t-1}$ relates the level of discouragement among individuals looking for a job (regardless of activity status) and the cyclical unemployment risk. As argued, the unemployment rate is not only observable for employers but also for those looking for a job who may feel more discouraged at times when the unemployment rate is high. Therefore, we believe $\beta_{3}$ to be positive.

$X_{i t}$ are the observed explanatory variables and $c_{i}$ is the individual-specific effect. It is important to take into account unobserved heterogeneity because ignoring it overestimates the degree of state dependence. On the other hand, the treatment of initial conditions is crucial in the estimation of dynamic panel data models given that the start of the observation window may not be the same as the beginning of the outcome experience. Following Wooldridge (2005), we find the density of the dependent variable from the second period onwards to be conditional on the initial condition and the average of the time-varying explanatory variables, $\bar{X}_{i} \cdot{ }^{5}$ Thus, $c_{i}$ is specified as follows:

$c_{i}=\alpha_{1}+\alpha_{2} u_{i 0} d_{i 0}+\alpha_{3}^{\prime} \overline{X_{i}}+\kappa_{i}$

\footnotetext{
${ }^{5}$ Following Stewart (2007), we add the time-averaged in order to allow for a correlation between the individual-specific effects and the time-varying variables.
} 
where $\kappa_{i}$ is assumed to follow a zero-mean normal distribution and variance $\sigma_{\kappa_{i}}^{2}$. Finally, $\varepsilon_{i t}$ is the idiosyncratic error term. Parameter estimates are obtained by Conditional Maximum Likelihood.

\section{Results}

The first column in Table 2 replicates the same model specified in Biewen and Steffes (2010). As expected, the existence of positive state dependence in unemployment is confirmed: past unemployment increases in itself the chances of current unemployment. However, its effect is greater during periods of low unemployment as shown by the negative sign of the interaction between past unemployment status and the cyclical unemployment rate. Thus, the results show evidence of stigma effects in the Spanish labour market.

\section{[TABLE_2]}

Discouragement also plays a significant role in explaining the persistence of unemployment as shown in the second column in the Table. Indeed, state dependence in unemployment increases in size and explanatory power in relation to the individual level of discouragement when looking for a job. As a matter of fact, Average Partial Effects indicate that being unemployed and believing one's chances of finding a job are 'very bad' increases by $7.4 \%$ the probability of still being unemployed the following year. Instead, among those that feel their chances of finding a job are 'good', this percentage falls to $4.7 \%$. Interestingly enough, the scarring effect of unemployment is positive and highly significant even among those that are well-motivated to find a job.

As for the unemployed not looking for a job, state dependence in unemployment exists but is not especially large. This is readily explained by the fact that those not looking for a job may be in a variety of different situations -for instance, waiting to start a job or preparing for retirement.

Our model confirms the existence of stigma effects in Spain but shows how they depend on the individual level of discouragement and only affect those that believe their chances of finding a job are 'not good not bad', 'bad' or 'very bad'. Instead, among individuals that feel positive about their chances of finding a job, no evidence of stigmatisation is found. For example, they might show greater enthusiasm for themselves in job interviews, which may avoid stigmatisation. Similarly, our model indicates that stigma effects are not relevant for unemployed people not looking for a job, which goes in line with the hypothesis of stigmatisation.

Moreover, note the positive association between the cyclical unemployment risk and the different levels of discouragement. The results suggest that in years when the unemployment rate rises, people become aware that finding a job is more difficult and hence feel more discouraged.

The other variables have the expected sign -for instance, married individuals and university degree holders are less likely to be unemployed while immigrants are more likely to be so. Unobserved heterogeneity is positive and highly significant, underlying the importance of controlling for it. 


\section{Conclusions}

Our results suggest that stigma and discouragement explain the persistence of unemployment in the labour market. While it is true that the stigmatisation of unemployed individuals becomes less important during periods of a rising unemployment rate, this effect is counter-balanced by the increased discouragement of those searching for a job.

\section{Acknowledgements}

Financial support is greatly acknowledged from the Spanish project ECO2010-21668C03-02 and XREPP (Direcció General de Recerca).

\section{References}

Arulampalam, W., A. Booth, and M. Taylor (2000): “Unemployment persistence," Oxford Economic Papers, 52(1), 24-50.

Biewen, M., and S. Steffes (2010): "Unemployment persistence: Is there evidence for stigma effects?,” Economics Letters, 106(3), 188-190.

Blau, D.M., and P.K. Robins (1990): "Job search outcomes for the employed and unemployed,” The Journal of Political Economy, 98(3), 637-655.

Clark, A.E., Y. Georgellis, and P. Sanfey (2001): "Scarring: the psychological impact of past unemployment,” Economica, 68, 221-241.

Lockwood, B. (1991): "Information externalities in the labour market and the duration of unemployment,” The Review of Economic Studies, 58(4), 733-753.

Omori, Y. (1997): “Stigma effects of unemployment," Economic Inquiry, 35(2), 394416.

Stewart, M.B. (2007): "The interrelated dynamics of unemployment and low-wage employment,” Journal of Applied Econometrics, 22(3), 511-531.

Wooldridge, J.M. (2005): "Simple solutions to the initial conditions problem in dynamic, non linear panel data models with unobserved heterogeneity," Journal of Applied Econometrics, 20, 39-54. 


\section{APPENDIX}

Figure A.1. Unemployment rate by year and region in Spain and unemployment trend (fitted values)

[FIGURE_1]

Source: Own calculations on the ECHP. 
Table 1. Unemployment rate, percentage of unemployed feeling they have 'very bad' chances to find a job and unemployed looking for a job in Spain, 19942001

\begin{tabular}{lcccccccc}
\hline & $\mathbf{1 9 9 4}$ & $\mathbf{1 9 9 5}$ & $\mathbf{1 9 9 6}$ & $\mathbf{1 9 9 7}$ & $\mathbf{1 9 9 8}$ & $\mathbf{1 9 9 9}$ & $\mathbf{2 0 0 0}$ & $\mathbf{2 0 0 1}$ \\
\hline Unemployment rate & 23.71 & 22.62 & 23.91 & 22.57 & 18.45 & 15.38 & 13.62 & 12.01 \\
\% of unemployed \& 'very bad' chances & 41.73 & 46.28 & 38.67 & 29.81 & 23.26 & 19.34 & 15.30 & 13.77 \\
\% of unemployed looking for a job & 94.02 & 95.50 & 95.87 & 95.33 & 96.44 & 95.65 & 96.46 & 92.92 \\
\hline
\end{tabular}

Source: Own calculations on the ECHP. 
Table 2. Dynamic random-effects probit model for unemployment status in Spain (selected parameters), $1994-2001$ (standard errors in parenthesis\}

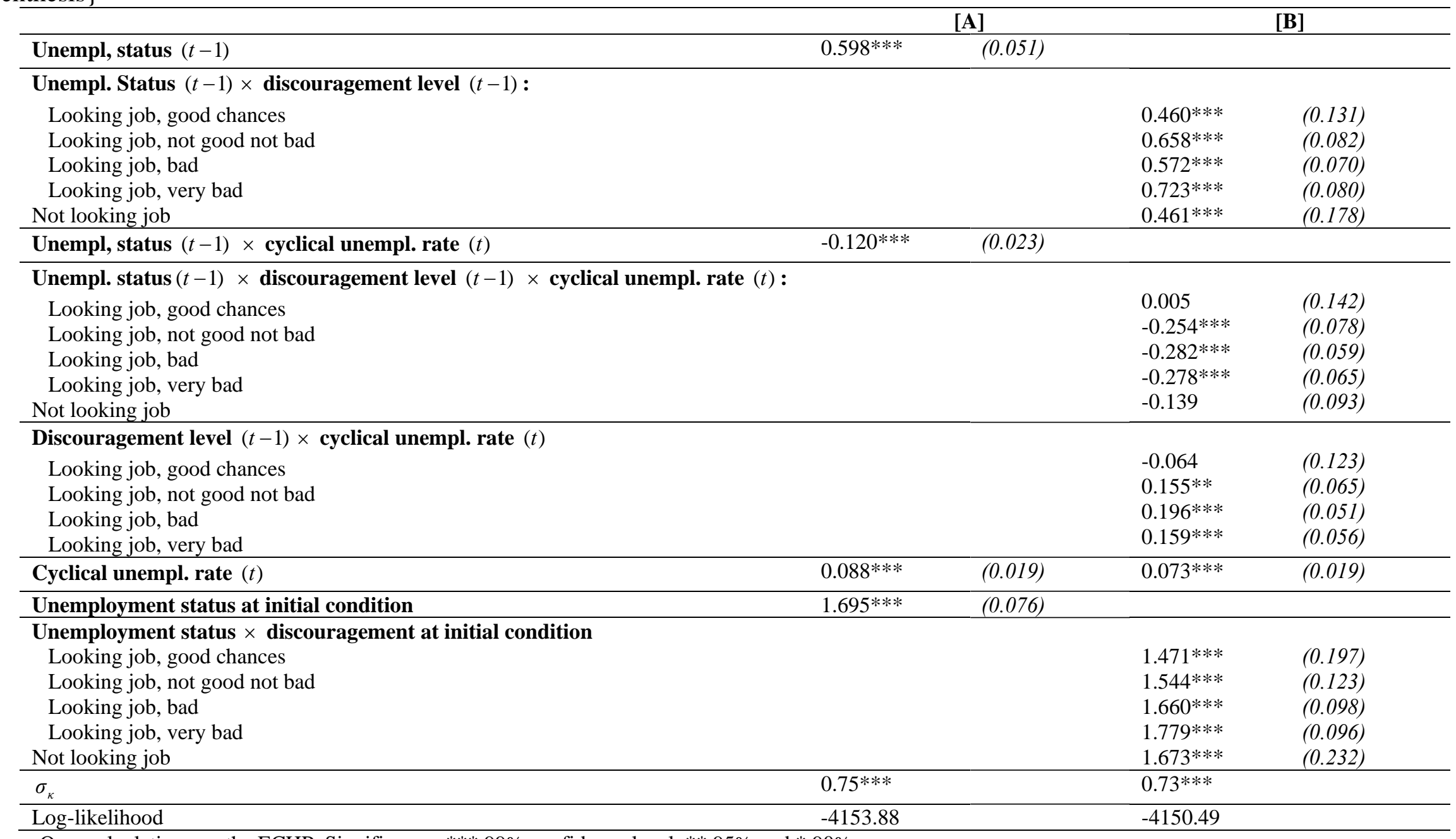

Source: Own calculations on the ECHP. Significance: *** 99\% confidence level, ** 95\% and * 90\%. 